\title{
Effects of Ocean Acidification and Sea-Level Rise on Coral Reefs
}

Coral reefs are vital to the long-term viability of coastal societies, providing economic, recreational, and aesthetic value from which coastal communities thrive. Some of the services that coral reefs provide include protection from storm waves, nurseries and habitats for commercially important fish species, and production of sand for beaches. Coral reefs develop over thousands of years as tropical marine organisms build skeletons of calcium carbonate $\left(\mathrm{CaCO}_{3}\right)$ minerals to form a three-dimensional structure (fig. 1). This process, called biogenic calcification, occurs when calcium combines with carbonate $\left(\mathrm{CO}_{3}{ }^{2-}\right)$ or bicarbonate $\left(\mathrm{HCO}_{3}^{-}\right)$ions in seawater to produce $\mathrm{CaCO}_{3}$, carbon dioxide $\left(\mathrm{CO}_{2}\right)$, and water $\left(\mathrm{H}_{2} \mathrm{O}\right)$. Over time as these organisms grow and die, their skeletons break down and become calcium carbonate sediments. These sediments fill in the framework of the reef and eventually become cemented together, constructing the foundation for continued upward growth of the reef structure. The infilling of the reef framework with sediments is what allows vertical accretion over time and enables reef growth to keep up with sea-level rise. Calcification is a reversible process. When the amount of $\mathrm{CO}_{2}$ in seawater increases, it causes dissolution of carbonate sediments (fig. 2).

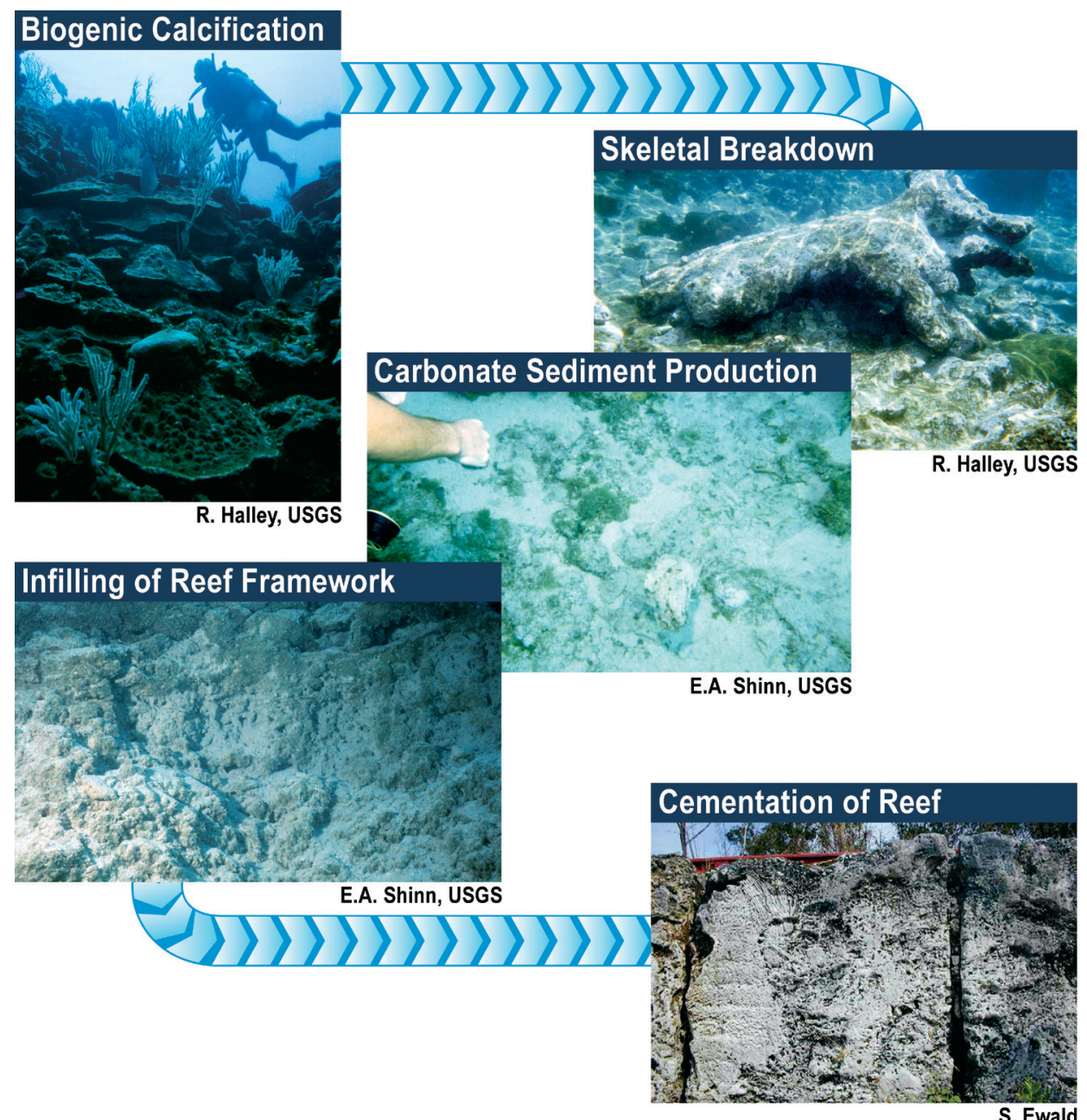

Figure 1. Formation of the three-dimensional structure of coral reefs.
As $\mathrm{CO}_{2}$ increases in the atmosphere, more is absorbed by the surface of the ocean, where it combines with seawater to make a weak acid called carbonic acid $\left(\mathrm{H}_{2} \mathrm{CO}_{3}\right)$. This process, called ocean acidification, causes a decrease in seawater $\mathrm{pH}$ (or increase in acidity) that can result in a decrease in biogenic calcification rates, dissolution of carbonate sediments, and loss of reef structure. One of the primary concerns associated with ocean acidification is whether coral reefs will be able to continue to grow at a rate fast enough to keep up with rising sea level and to sustain reef structure, or whether the existing structure will begin to erode away.

\section{U.S. Geological Survey (USGS) sci-} entists are developing comprehensive records of historical and modern coral reef growth and calcification rates relative to changing seawater chemistry resulting from increasing atmospheric $\mathrm{CO}_{2}$ from the pre-industrial period to the present. These records will provide the scientific foundation for predicting future impacts of ocean acidification and sealevel rise on coral reef growth. Changes in coral growth rates in response to past changes in seawater $\mathrm{pH}$ are being examined by using cores from coral colonies.

Historical calcification rates are being estimated by measuring the linear growth rate and density of the coral skeletons. Since the chemical composition of coral skeletons changes in response to changes in seawater chemistry, changes in historical seawater $\mathrm{pH}$ are being reconstructed by measuring boron isotope concentrations in the coral skeletons (fig. 3). Modern-day rates of coral reef community calcification are being determined by measuring changes in seawater chemistry over time using large incubation chambers to trap seawater over reef communities on the seafloor (fig. 4). These measurements are made at modern-day seawater $\mathrm{pH}$ and $\mathrm{pCO}_{2}$ (partial pressure 


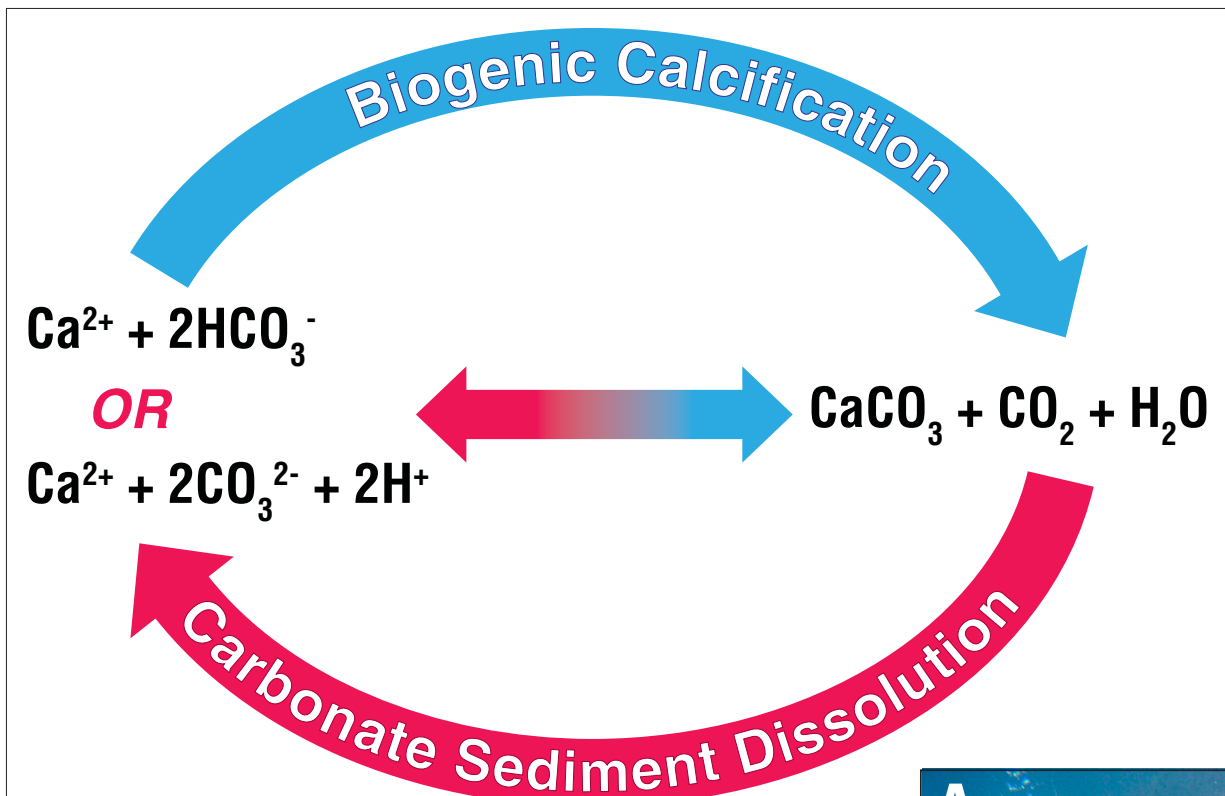

of $\mathrm{CO}_{2}$ ). Predictions of the response of coral reef growth to future $\mathrm{CO}_{2}$ levels are also being made through in situ experiments with these incubation chambers. For these experiments, gas equilibrators are connected to the incubation system and used to elevate $\mathrm{CO}_{2}$ levels to match predicted levels out to the year 2100 . Field work for this project is currently underway with study sites located in south Florida, Dry Tortugas National Park, Puerto Rico, and the U.S. Virgin Islands. Support for this project is from the USGS Coral Reef Ecosystem STudies (USGS CREST) project and the USGS Mendenhall Fellow Program.

Figure 2. Chemical reactions associated with biogenic calcification and carbonate sediment dissolution.

Figure 3. Historical coral growth rates and seawater chemistry are reconstructed from the density, growth, and chemistry of coral skeleton cores. A) USGS scientists collecting a core from a coral head by drilling into the coral. B) X-ray of a coral core showing growth bands of the skeleton. An annual band consists of a couplet of high-density (dark) and low-density (light) bands deposited during summer and winter months, respectively. The vertical graph shows variation in skeletal density. Note that growth rates vary from year to year.

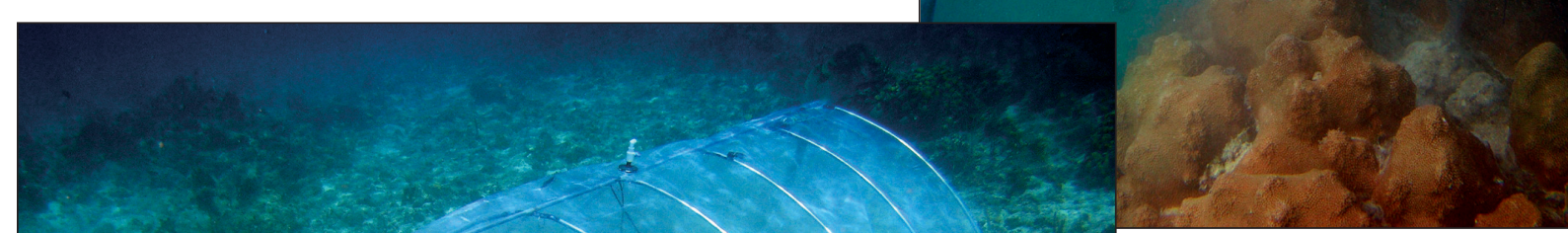

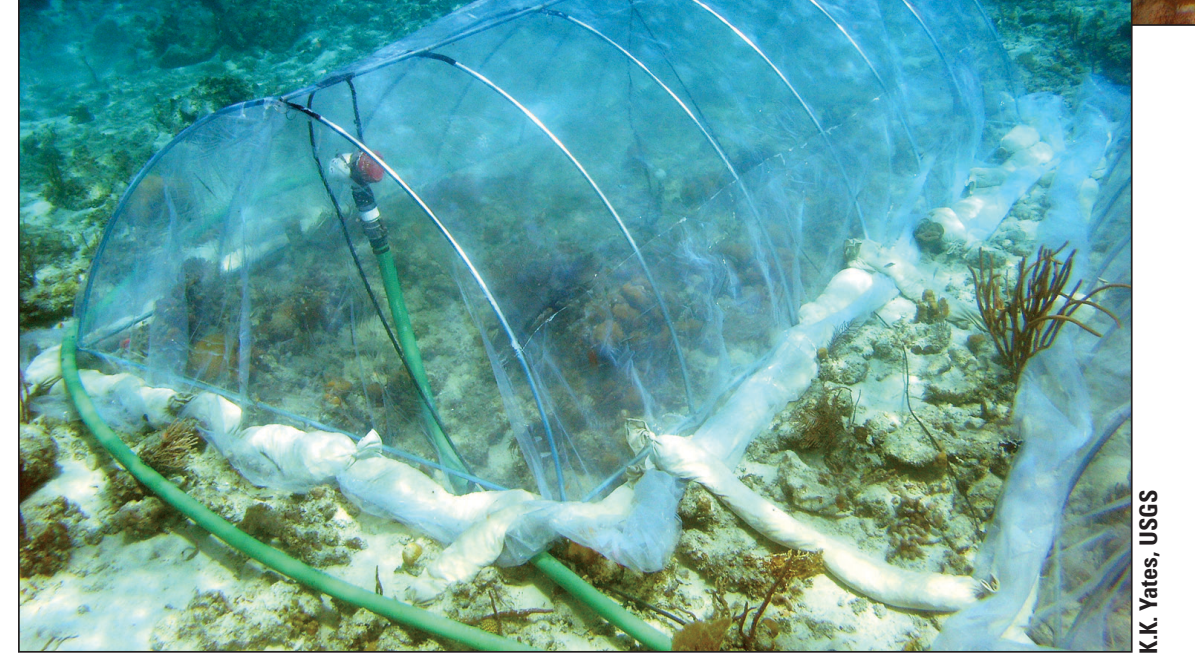

Figure 4. Modern growth rates of coral reef habitats and seawater chemistry are measured using a large (approximately $2.5 \mathrm{~m} \times 5 \mathrm{~m} \times 1.5 \mathrm{~m}$ ) seafloor incubation chamber, the Submersible Habitat for Analyzing Reef Quality (SHARO). The SHARO is also used for in situ experiments that measure growth rates of coral reef habitats subjected to levels of $\mathrm{CO}_{2}$ predicted for the future.
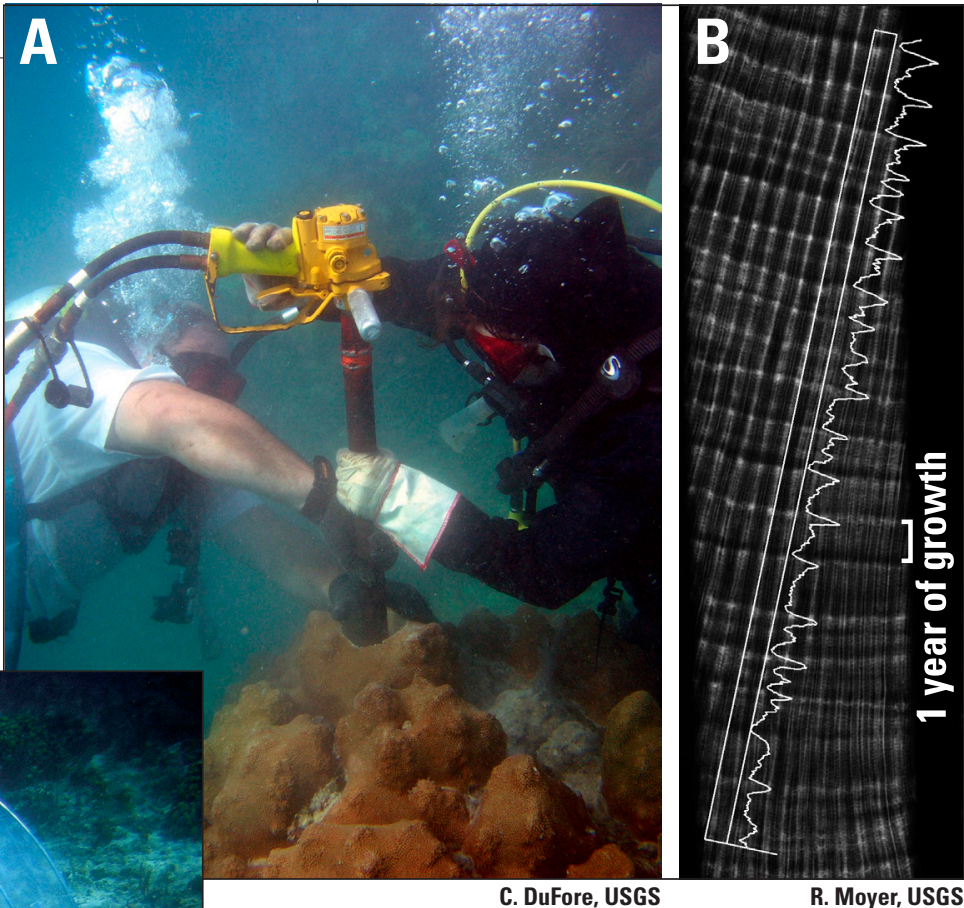

R. Moyer, USGS

\section{Contact Information:}

K.K. Yates

Biogeochemist

U.S. Geological Survey

St. Petersburg Science Center 600 4th Street South

St. Petersburg, FL 33701

PH: 727-803-8747 x3059

FAX: 727-803-2031

Email:kyates@usgs.gov

\section{R.P. Moyer}

Mendenhall Fellow

U.S. Geological Survey

St. Petersburg Science Center 600 4th Street South

St. Petersburg, FL 33701

PH: 727-803-8747 ×3030

FAX: 727-803-2031

Email: rmoyer@usgs.gov

http://coastal.er.usgs.gov/crest/ 